\title{
Analysis of the coupled electro-osmotic and mechanical consolidation in clayey soils
}

Sara Gargano MEng

PhD student, Department of Civil, Architectural and Environmental

Engineering (DICEA), University of Napoli Federico II University, Naples,

Italy (corresponding author: sara.gargano@unina.it)

\section{Stefania Lirer PhD}

Associate Professor, Department of Sustainability Engineering,

University Guglielmo Marconi, Rome, Italy
Alessandro Flora PhD

Associate Professor, Department of Civil, Architectural and

Environmental Engineering (DICEA), University of Napoli Federico II

University, Naples, Italy

Electrokinetic (EK) treatment is a possible attractive way to speed up the consolidation of fine-grained dredged sediments. The effectiveness of this method depends on the complex physical-chemical interaction between soil particles, interstitial fluid and pollutants. This paper presents the experimental laboratory results obtained by inducing mechanical and EK consolidation in a fine-grained dredged material. Then, a finite-difference numerical code implemented by the authors able to solve the large and small strain consolidation equations (Lassec1), including the electro-osmotic flow, is described along with the theoretical simplifications adopted and the calibration procedure required. The experimental results have been numerically simulated, showing the ability of Lassec1 to reproduce the coupled mechanical and electrical consolidation processes, highlighting that under very low stress levels it is necessary to take into account the highly non-linear soil behaviour, and thus the large strain theory is needed to obtain a reliable prediction of the consolidation process. With this aim, special laboratory devices are necessary for a good calibration of the permeability function and of the stress-strain relationship at very low stress levels.

\section{Notation}

A material constant (Equation 4)

$A_{\text {c }} \quad$ area of the cross-section

$B \quad$ material constant (Equation 4)

C material constant (Equation 5)

$c_{\mathrm{v}} \quad$ coefficient of consolidation $\left(\mathrm{m}^{2} / \mathrm{s}\right)$

$D \quad$ material constant (Equation 5)

$E_{\text {ed }} \quad$ oedometric modulus

$e$

$e_{0}$

$G_{\mathrm{S}}$

$H$

$H_{\mathrm{O}}$

$i$

$i_{\mathrm{e}}$

$k$

$\begin{array}{ll}\beta_{1} & \text { material constant (Equation 9) } \\ \gamma_{\mathrm{w}} & \text { volume weight of water } \\ \Delta L & \text { distance between the electrodes } \\ \Delta z & \text { height of soil elements } \\ \Delta \Phi & \text { electrical potential difference } \\ \varepsilon & \text { dielectric constant of the pore fluid } \\ \zeta & \text { soil zeta potential } \\ \eta & \text { dynamic pore-fluid viscosity } \\ \rho_{\mathrm{s}} & \text { solid grains density } \\ \rho_{\mathrm{w}} & \text { water density } \\ \sigma & \text { total stress } \\ \sigma & \text { effective stress }\end{array}$

\section{Introduction}

Maritime transportation is becoming increasingly relevant in the world's economy. In recent years, the need to offer access and handling of last-generation ships (8000 or more twentyfoot equivalent units (TEUs)) has resulted in the increase of dredging activities in many countries across the world, with huge volumes of sediments to be disposed.

The policy of many European countries is now to consider dredged sediments as a resource (Apitz, 2010; Lirer et al., 2017) that can be re-used in civil fields (embankment, prefabricated elements, nourishments, dykes, bricks and so forth).

It is well known that dredged sediments are underconsolidated, with an extremely high water content, sometimes contaminated; therefore, their possible reuse in civil fields requires treatments such as dewatering, decontamination and stabilisation. Dewatering is a key process owing to the need 
to reduce the volume of the sediments and to improve their mechanical soil properties.

Electrokinetic (EK) treatments represent (Flora et al., 2017; Lockhart, 1983) a possible technique for inducing a water flow without hydraulic gradients: in this case, the water flow is activated when the soil volume is charged with low-voltage direct current by way of electrodes placed in the ground (Figure 1). The applied electrical potential difference induces ion migration within the fluid phase: the positively charged ionic species move through the medium to the cathode (negative pole), while the negatively charged ones move through the porous medium to the anode (positive pole). As the ions migrate, they drag their hydration water and cause a viscous drag of the water around them (electro-osmosis). It has been experimentally verified that the electric field also induces a desaturation front in the soil (Alshawabkeh et al., 2004) that starts from the anodic area and moves to the cathodic area. This different degree of saturation induces a water flow from the cathode to the anode, in the opposite direction to that caused by the electro-osmotic flow. When the two phenomena balance, the electro-osmotic consolidation will be complete.

The flow is initiated in the diffuse double layer, where there are significantly more cations than anions due to the proximity of the negatively charged surface of clayey particles. The electric field can also trigger the transportation of the colloidal state (electrophoresis), thus inducing a beneficial decontamination process. All the electrochemical processes mentioned above induce a significant irreversible change in the physico-chemical and mechanical properties of the treated soil.

In the literature, many experimental works (Bjerrum et al., 1967; Casagrande, 1948; Flora et al., 2016; Lo et al., 1991; Lockhart, 1983; Reddy et al., 2006) have verified the effectiveness of EK treatment both to accelerate the expulsion of water and to improve the strength and stiffness of clayey soils. These studies showed that the effectiveness of the EK treatment is linked not only to the mineralogical nature of the soil, but also

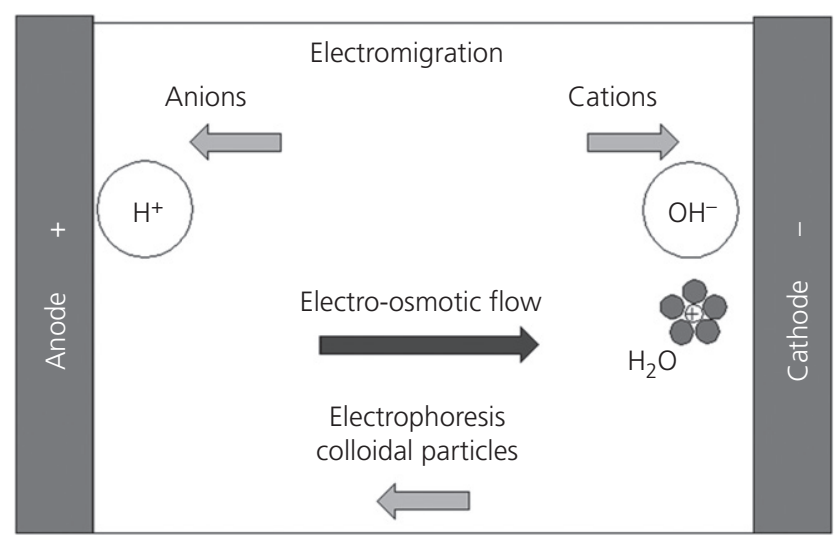

Figure 1. EK process induced by an electric field to the applied potential, the type of electrodes and the chemical composition of the interstitial fluid.

It should be noted that all the successful applications of EK involved soils of low salinity (the salt content in the pore water was less than $2 \mathrm{~g}$ sodium chloride/l or the equivalent). However, for clays with a high salt content in the pore water, such as marine sediments, limited data reported in the literature suggest that the high salinity can significantly decrease the electroosmotic flow in soil (e.g. Casagrande, 1948; Gray and Mitchell, 1967; Lockhart, 1983; Mitchell, 1993; Yeung, 1994).

Some analytical and numerical models have been developed to simulate the soil behaviour during electro-osmotic treatment. Esrig (1968) proposed a one-dimensional (1D) model to calculate the excess pore-water pressure. An analytical solution for electro-osmotic treatment, coupled with preloading, was presented by Wan and Mitchell (1976). However, the 1D analytical solutions for a uniform electric field may not be appropriate for most field applications due to the complexity of electrode configuration and boundary conditions. Lewis and Humpheson (1973) established the coupled governing equations of electric current and electro-osmotic flow to analyse the groundwater flow in two-dimensional (2D) electric fields, but soil settlement was not considered. Rittirong and Shang (2008) proposed a 2D finite-difference model to analyse indirectly the subsurface settlement and undrained shear strength according to the change of excess pore-water pressure and water discharge.

Most of the studies mentioned have assumed that the hydraulic, electrical and mechanical properties of soils remain constant during electro-osmotic consolidation. Recently, Hu et al. (2012) have demonstrated based on a numerical study that the changes in water content and soil density cannot be overlooked in order to correctly simulate the complex electro-osmotic process.

The purpose of this study is to develop a theoretical model to analyse the electro-osmotic consolidation of soils. Since soil properties vary with changes in water content and the degree of soil consolidation, the non-linear relationship among soil properties is incorporated into the model.

An experimental and numerical research activity was developed at the University of Naples Federico II to study the complex phenomena that occur during the electro-kinetic consolidation process, and also to verify the true applicability of this technique to real-scale sites. With this aim, two different laboratory devices (oedometric cells) have been developed to verify, at the laboratory scale, the effectiveness of electro-kinetic consolidation in the dewatering of low-permeability soils. In this paper, the experimental results obtained with these apparatuses are compared with the numerical results obtained from the finite-difference code, known as the large and small strain electro-osmotic consolidation code (Lassec1) developed by Gargano (2017) to simulate the complex 1D electro-mechanical 
consolidation process induced by the application of a mechanical load and a superimposed voltage gradient. In the following, the experimental activity will be first described and commented upon. This part of the research programme was needed to obtain good-quality first-hand experimental results, both for the numerical simulation of the consolidation process under different loading paths and for the calibration of the parameters of the numerical model. Then, the theoretical background used to implement the numerical code will be described, and finally the numerical simulations will be compared with the experimental results.

\section{Experimental study}

The experimental programme consists of oedometric tests carried out on a sandy clay with silt of high plasticity (Figure 2, Table 1).

The oedometric tests were carried out in two cells called a special oedometer (EdS) and an electro-osmotic cell $(\mathrm{CeO})$, as described in detail in Section 3. Such equipment has been designed with the purpose of carrying out oedometric tests with large displacements, applying mechanical loads and/or electric gradients. The tests were all performed on specimens reconstituted with water content $\left(w_{\mathrm{w}}\right)$ of 1.4 times the liquid limit $\left(w_{\mathrm{L}}\right)$. In this study, the soil was first washed with tap water and then tap water was used to saturate the specimens.

The experimental programme is summarised in Table 2: seven tests were performed in the $\mathrm{EdS}$ and one in the $\mathrm{CeO}$ by applying different load paths $(\mathrm{M}=$ mechanical, $\mathrm{ME}=$ mechanical and electrical simultaneously, $\mathrm{M}+\mathrm{E}=$ mechanical and electrical separately). The applied electric gradients $(\Delta \Phi / L)$ vary between 0.6 and $2 \mathrm{~V} / \mathrm{cm}$. Two tests were carried out in a traditional oedometer as well: one on reconstituted material (ET1) at high-stress

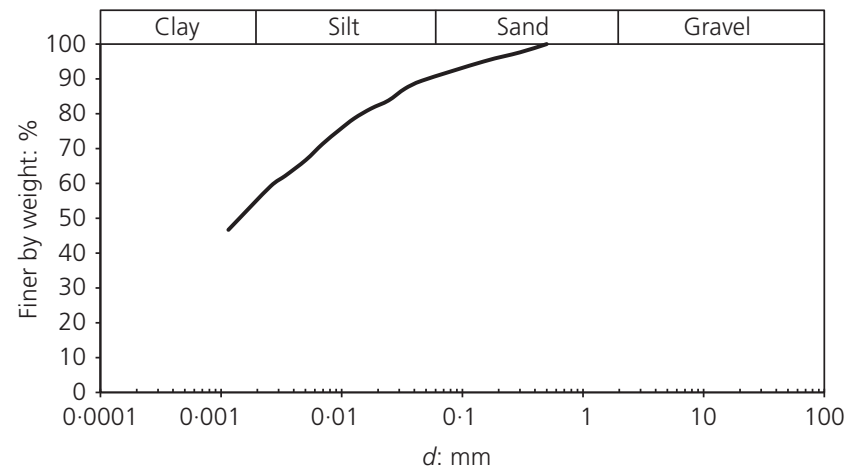

Figure 2. Grain-size distribution of the tested soil

Table 1. Physical properties of the tested soil (Figure 2)

\begin{tabular}{lccc}
$\begin{array}{l}\text { Specific } \\
\text { gravity, } G_{\mathbf{s}}\end{array}$ & $\begin{array}{c}\text { Liquid limit, } \\
\boldsymbol{W}_{\mathbf{L}}\end{array}$ & $\begin{array}{c}\text { Plastic limit, } \\
\boldsymbol{W}_{\mathbf{P}}\end{array}$ & $\begin{array}{c}\text { Plastic } \\
\text { index, PI }\end{array}$ \\
\hline 2.72 & 0.59 & 0.23 & 0.36
\end{tabular}

Table 2. Experimental programme of laboratory tests

\begin{tabular}{|c|c|c|c|c|c|c|}
\hline $\begin{array}{l}\text { Name } \\
\text { test }\end{array}$ & $\begin{array}{l}\text { Type } \\
\text { load }\end{array}$ & Cell & $e_{0}$ & $\begin{array}{c}\sigma_{\mathrm{v}, \max }^{\prime}: \\
\mathrm{kPa}\end{array}$ & $\Delta \Phi: \mathbf{V}$ & $\begin{array}{l}\Delta \Phi / L: \\
\mathrm{V} / \mathrm{cm}\end{array}$ \\
\hline M1 & $\mathrm{M}$ & $\mathrm{EdS}$ & $2 \cdot 4$ & 15 & - & - \\
\hline E1 & ME & EdS & $2 \cdot 3$ & 15 & 6 & $0 \cdot 6$ \\
\hline E2 & ME & EdS & $2 \cdot 2$ & 15 & 12 & $1 \cdot 2$ \\
\hline E3 & ME & EdS & $2 \cdot 2$ & 15 & 20 & 2 \\
\hline M2 & $M$ & EdS & $2 \cdot 1$ & 30 & - & - \\
\hline E4 & ME & EdS & $2 \cdot 1$ & 30 & 12 & $1 \cdot 2$ \\
\hline EA1 & $M+E$ & EdS & $2 \cdot 2$ & $4 \cdot 4$ & 12 & 1 \\
\hline A1 & $M+E$ & $\mathrm{CeO}$ & $2 \cdot 2$ & $4 \cdot 4$ & 20 & 1 \\
\hline Post $A 1^{a}$ & M & Trad $^{b}$ & $1 \cdot 7$ & 5000 & - & - \\
\hline ET1 & M & $\operatorname{Trad}^{\mathrm{b}}$ & $2 \cdot 3$ & 5000 & - & - \\
\hline
\end{tabular}

${ }^{\mathrm{a}}$ Test on the specimen taken after test $\mathrm{A} 1$ ${ }^{\mathrm{b}}$ Trad, traditional

levels $(5000 \mathrm{kPa})$, and one on a specimen retrieved from the $\mathrm{CeO}$ at the end of test $\mathrm{A} 1$ (post $\mathrm{A} 1^{\mathrm{a}}$, Table 2).

\subsection{Experimental devices}

\subsubsection{The EdS}

The special floating oedometer (Figure 3) has been developed (Flora et al., 2016) to carry out oedometric tests on very soft under-consolidated specimens that undergo extremely large deformations during the consolidation process. The mechanical vertical load and the vertical voltage gradient can be applied either separately or together, thus enabling different combinations of mechanical (M) and electro-kinetic (E) consolidation processes. The vertical settlements $(s)$ are measured by means of a linear variable differential transformer (LVDT). The

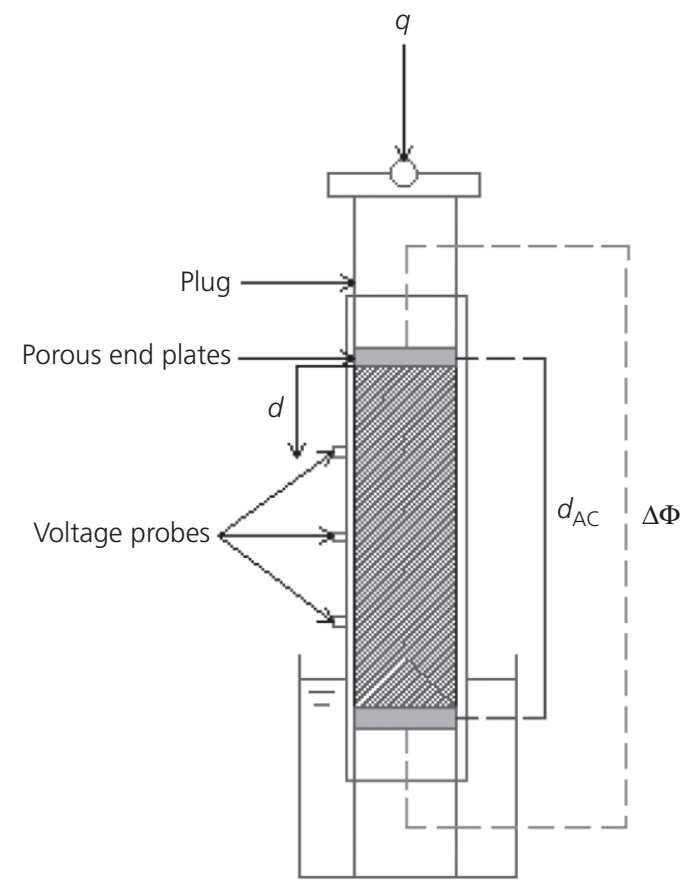

Figure 3. Sketch of the EdS 
oedometer is floating to minimise the effects of tangential stress on the soil-poly(methyl methacrylate) (PMMA) interface.

The test set-up is made of a PMMA cylindrical cell (cell height $=20 \mathrm{~cm}$, internal diameter $D=5 \mathrm{~cm}$ and thickness $s=0.3 \mathrm{~cm}$ ) in which the specimen is placed (the specimen height $H$ is $13 \mathrm{~cm}$ ). The specimen is confined by two floating end caps, on which $1 \mathrm{~cm}$ thick graphite (conductive) porous plates are placed. Three steel probes are placed through the confining cylinder into the soil to measure the electric potential along the specimen height $(y)$ by means of a digital multimeter. During the electrified tests, the upper (anode) and the lower (cathode) conductive end plates were connected to a DC power supply, operating under constant voltage difference $(\Delta \Phi)$, thus causing an electrically driven water flow towards the bottom base of the apparatus.

During the application of the electric field, it is possible to measure the intensity of the electric current $(i)$ and the potential difference $(\Delta \Phi)$ along the height of the specimen $(y)$ with the previously mentioned steel probes.

\subsubsection{The $\mathrm{CeO}$}

The $\mathrm{CeO}$ (Figure 4) was designed to induce a horizontal electro-osmotic flow within a larger volume of soil under controlled vertical load in oedometric conditions. The elements that make up the cell are: a PMMA rectangular box, carbon fibre plates (anode and cathode), an electrical circuit, a DC power supply, a display for electric measurement (current intensity $i$ and potential difference $\Delta \Phi$ ), an LVDT, two tensiometers and two volume gauges. The PMMA cell walls have a thickness of $30 \mathrm{~mm}$, an area $A$ of $280 \times 170 \mathrm{~mm}^{2}$ and a height $H$ of $200 \mathrm{~mm}$. At the head of the specimen, a uniformly distributed load can be applied through a pressurised membrane with a rigid bottom. The two conductive porous plates are placed on the side of the box (Figure 4), acting as anode and cathode when connected to a DC power supply. The volume of water expelled during the tests is collected and measured through two volume gauges connected at the two ends of the specimen. During the activation of the electric field, the anode is closed and only the cathode expels water. Finally, two tensiometers are placed in the soil near the anode and cathode, to measure the suction during the test.

\subsection{Experimental results}

\subsubsection{Results of tests in EdS apparatus}

Figure 5 shows the results of some of the oedometric tests carried out in the EdS (E1, E2, E3, E4, M1 and M2) and a test performed in traditional oedometers (ET1) in the semilogarithmic plane of the void ratio $(e)$ - effective vertical stresses $\left(\sigma_{\mathrm{v}}^{\prime}\right)$.

Tests E1, E2, E3 and M1 (Figure 5(a)) were carried out with the same mechanical load path up to an effective stress of $8 \mathrm{kPa}$ : in the subsequent load increase $(8-15 \mathrm{kPa})$, in tests E1, E2 and E3 an electric field was applied simultaneously (ME load, Table 2). Tests E4 and M2 (Figure 5(b)) were carried out with the same mechanical load path up to an effective stress of

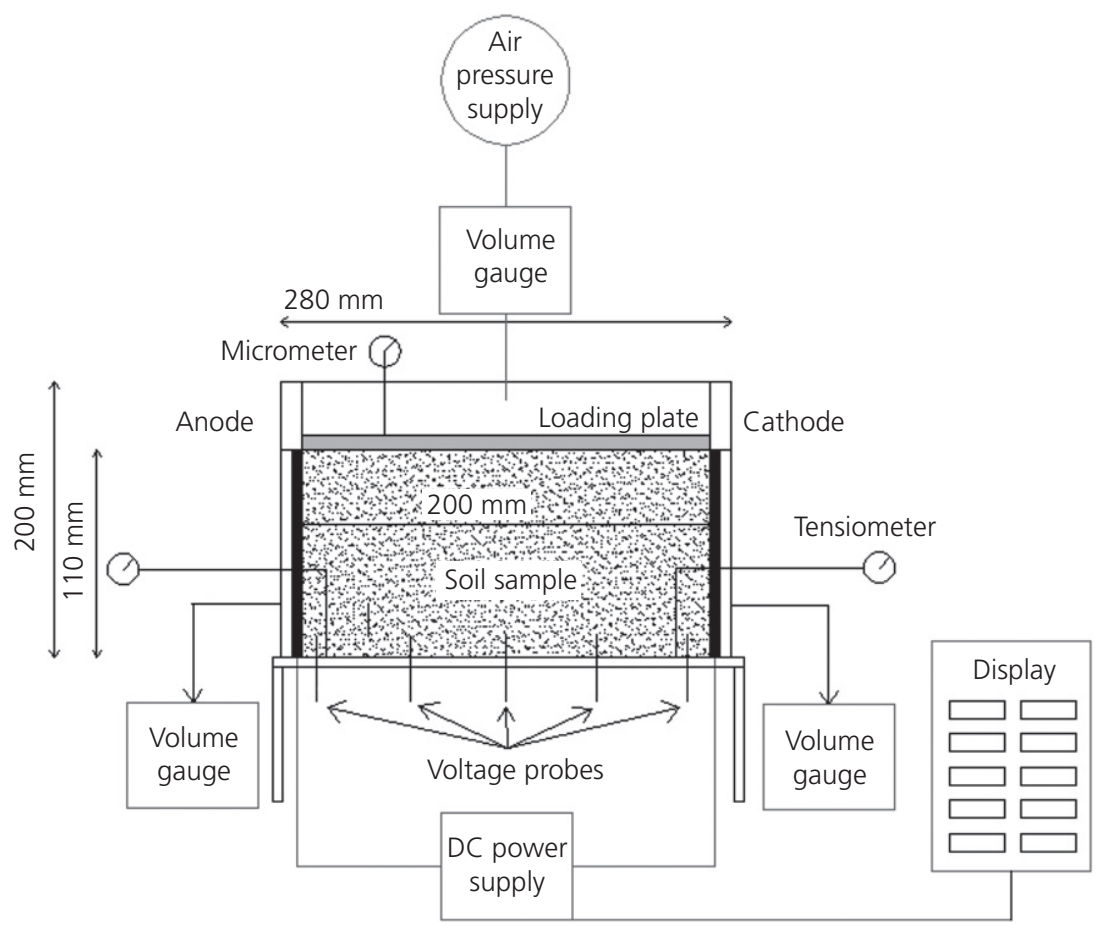

Figure 4. Sketch of the $\mathrm{CeO}$ 


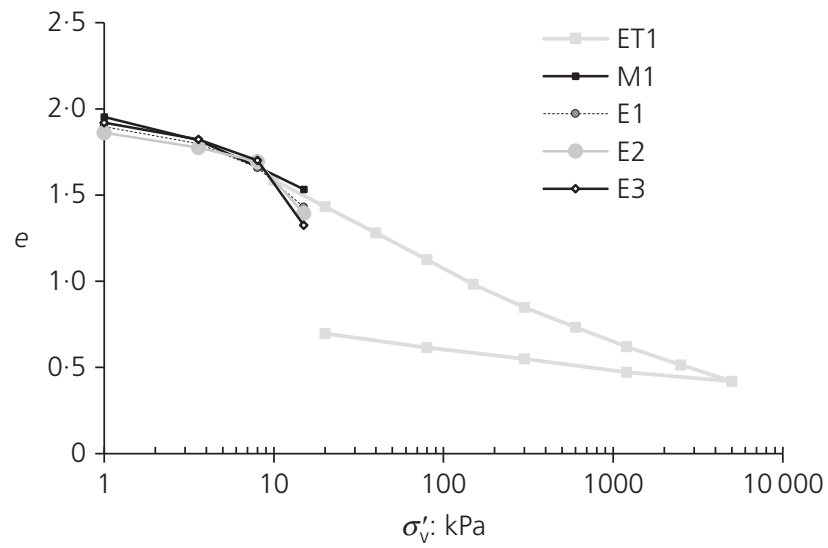

(a)

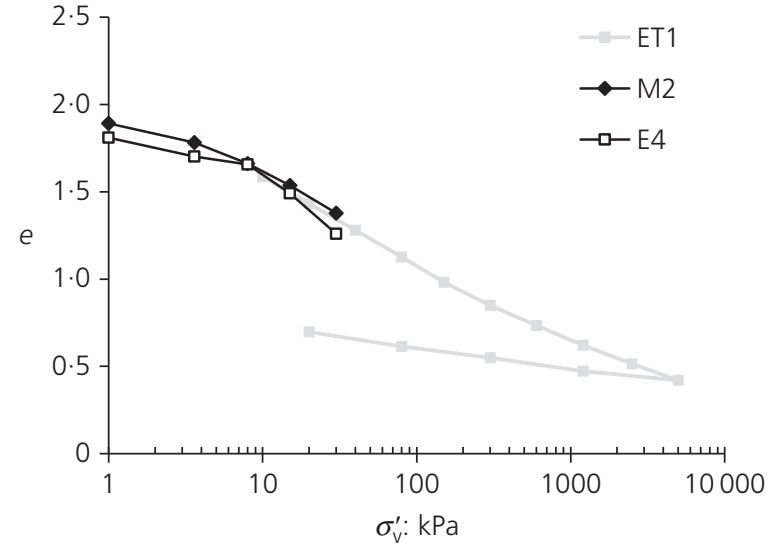

(b)

Figure 5. Results of oedometer tests (Table 2): void ratio (e) against vertical effective stress $\left(\sigma_{\mathrm{v}}^{\prime}\right)$ : (a) Test ET1, M1, E1, E2, E3; (b) Test ET1, M2, E4
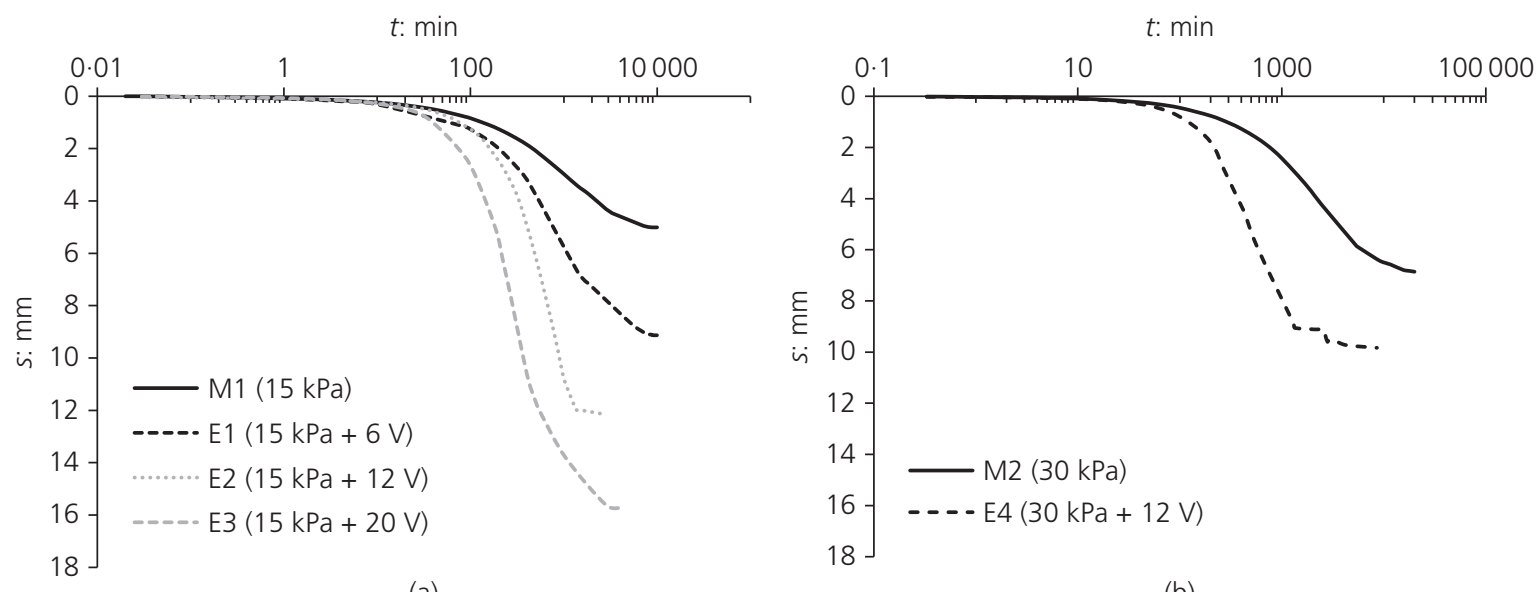

(a)

(b)

Figure 6. Results of oedometer tests (Table 2): settlements (s) against time ( $t$ ): (a) Test M1, E1, E2, E3; (b) Test M2, E4

$15 \mathrm{kPa}$ : in the subsequent load increase $(15-30 \mathrm{kPa})$, in the test E4, an electric field was applied simultaneously (ME load, Table 2).

Different electric potential differences $(\Delta \Phi)$ were applied at the ends of the specimen: $6 \mathrm{~V}$ (E1 test), $12 \mathrm{~V}$ (E2 and E4 tests) and $20 \mathrm{~V}$ (E3 test).

As previously mentioned, the electric field generates a nonhomogeneous variation of stress state in the specimen connected to a partial (and non-homogeneous) soil desaturation. Therefore, at the end of electro-osmotic consolidation, the stress state is not known, and should be expressed in terms of net stresses $(\sigma-u)$ rather than effective.

In Figure 6, the results in terms of settlement plotted against time for the same mechanical load increase $(8-15 \mathrm{kPa}$ for tests E1, E2, E3 and M1, 15-30 kPa for tests E4 and M2) are shown. It is noted that the simultaneous application of the electric field (tests E1, E2, E3, E4) induces higher settlements in the specimen due to the electro-osmotic flow. The electro-osmotic flow, and the resulting specimen settlement (Figures 6(a) and 6(b)), is also directly proportional to the applied electrical potential (higher for E3 test).

During tests E1, E2, E3 and E4, the current intensity (i) was also measured: there is a direct proportionality between the measured values of the latter and the trend of the settlements in time (Figure 7): the current intensity in test E2 tends to decrease in time due to the reduced mobility of the ionic species present in the porous fluid. This decrease in the current intensity tends to slow the electro-osmotic water flow and thus the settlements of the specimen.

\subsubsection{Results of tests in the $\mathrm{CeO}$}

In the experiment carried out in the $\mathrm{CeO}$ (A1, Table 2), the specimen was first subjected to a mechanical loading path up to a maximum effective stress $\sigma_{\mathrm{v}, \max }^{\prime}=4.4 \mathrm{kPa}$ (Figure 8), 


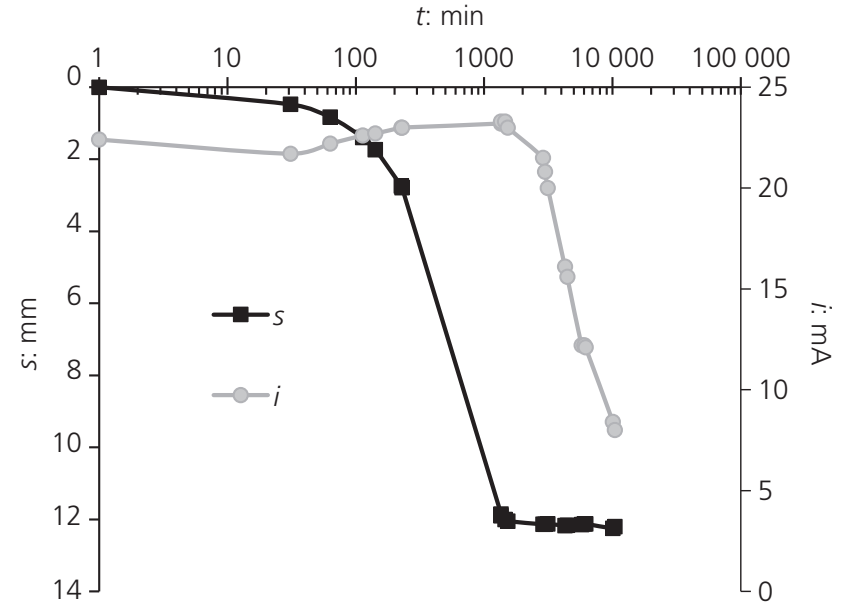

Figure 7. Measurements of the specimen settlements $(s)$ and the current intensity (i) during the test E2 (Table 2)

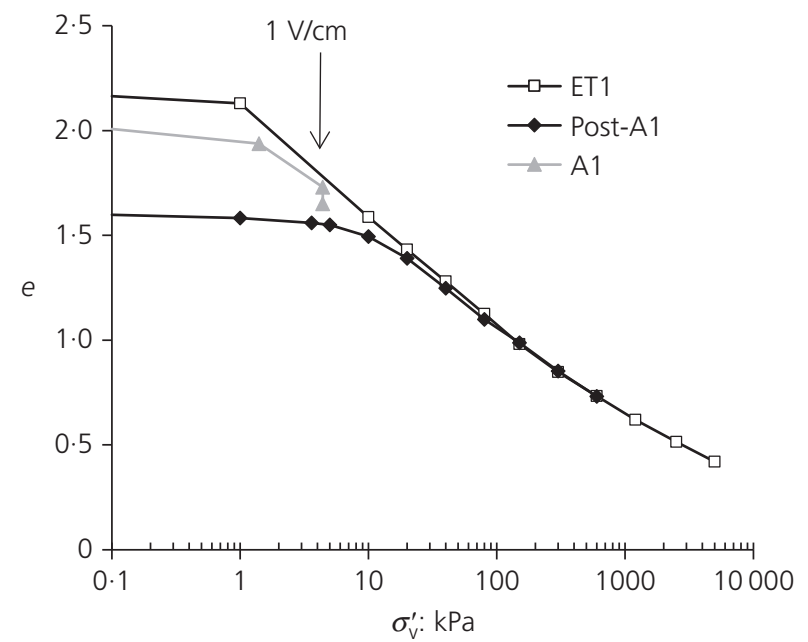

Figure 8. Results of $A 1$, post $A 1$, ET1 tests (Table 2 ) in the void ratio-effective vertical stress plane

allowing water drainage from both the sides of the sample. At the end of the primary consolidation $\left(s_{100}=9.6 \mathrm{~mm}\right.$, Figure 9), an electrical potential gradient of $1 \mathrm{~V} / \mathrm{cm}$ was applied inside the specimen - without changing the mechanical load - allowing water to drain only from one end of the specimen (cathode side). Electro-osmotic consolidation induces a restart of the settlements $\left(s_{\mathrm{ek}}\right)$, which reach almost $40 \%$ of those measured at the end of primary consolidation $\left(s_{100}\right)$. Water flow tends to decrease over time due to the reduced mobility of the ions in the porous fluid, and due to the partial desaturation of the soil near the anode.

The suction values recorded by the tensiometer in the soil near the anode (Figure 10) increase during the test, reaching a maximum of about $16 \mathrm{kPa}$, in line with the experimental data reported in the literature (Lee, 2007).

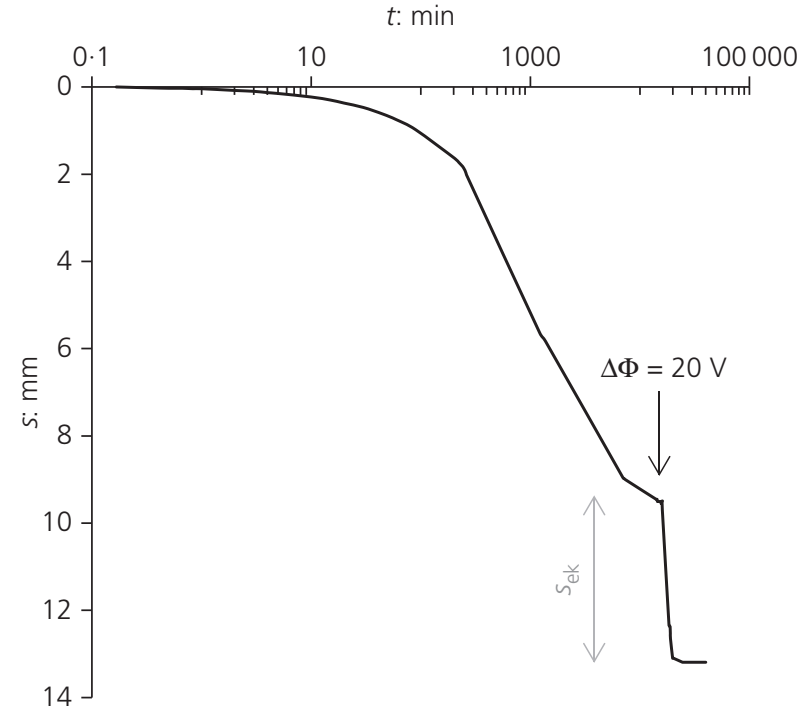

Figure 9. Measurements of the specimen settlements $(s)$ during the time $(t)$ for the test $\mathrm{A} 1$ (Table 2 )

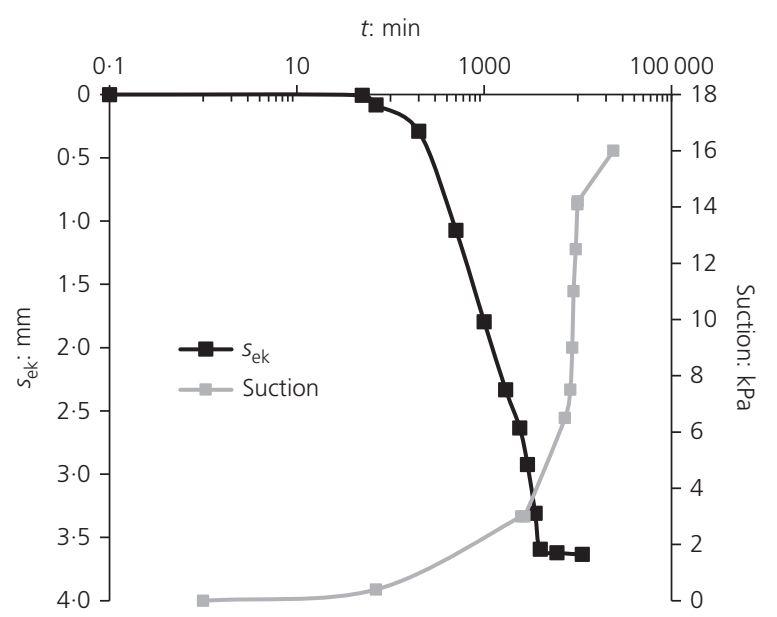

Figure 10. Measurements of the specimen settlements $\left(s_{e k}\right)$ and suction during the application of the electric field in the test A1 (Table 2)

At the end of the test, the $\mathrm{pH}$ of the water expelled from the cathode was also measured: it is well known (Mitchell, 1993) that in this zone the $\mathrm{pH}$ increases due to the alkaline reactions owing to the hydrolysis of water and subsequent production of hydroxide ions $\left(\mathrm{OH}^{-}\right)$. The $\mathrm{pH}$ of the porous fluid shifts in this test from the initial value of 8 to the final value of 13 .

\section{Numerical study}

The authors have implemented a finite-difference numerical code (Lassec1) to simulate the electro-mechanical consolidation process in 1D conditions. Lassec1 solves the large strain consolidation equation (Gibson et al., 1967) or the Terzaghi consolidation equation (Terzaghi, 1943), both modified to include the electro-osmotic flow. 


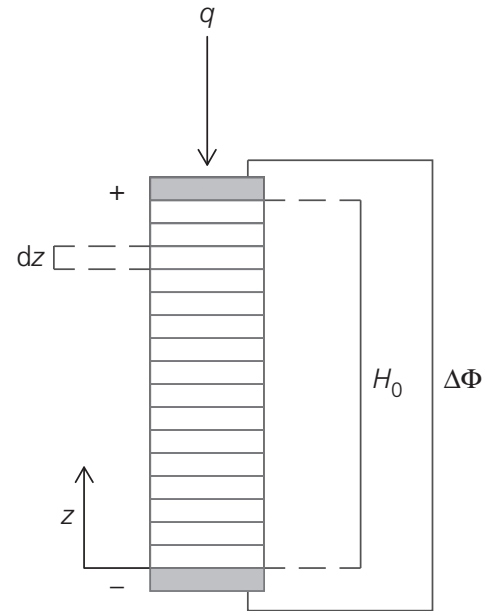

Figure 11. Geometry for the configuration used

The geometry of the compressible saturated soil model considered in Lassec1 is shown in Figure 11: the 1D soil column of height $H_{0}$ is discretised in $n$ elements of height $\Delta z$, with the $z$ axis oriented upwards (against gravity). In order to have a coordinate system suitable at the large strain case too, the so-called material coordinates (Ortenblad, 1930) have been adopted.

The cathode (-) and anode $(+)$ are placed at the two extremes of the soil column. The initial soil void ratio $\left(e_{0}\right)$ is assumed constant along the height of the specimen.

The initial conditions $(t=0)$ can be introduced in terms of applied mechanical load $(q)$ or/and applied electrical potential difference $(\Delta \Phi)$. The mechanical load $(q)$ is applied at the top boundary, thus simulating the possible superimposition of another layer of soil in an ongoing dredging activity. In this case, assuming that the self (for under-consolidated soils) or the overburden loads are applied at $t=0$, the initial stress condition in the soil mass corresponds to pore pressures equal to total stresses and also equal to the applied load (oedometric condition).

For the applied electrical potential difference $\Delta \Phi$, the initial condition $(t=0)$ is expressed with a second-order polynomial that represents its distribution along the height of the specimen at the start of the electro-osmotic process.

The boundaries of the mass can be specified as drained (Dirichlet condition, in mathematical terms) or impermeable (Neumann condition). The hydraulic boundary conditions are related to the possibility of water to access the electrodes. If the electrodes are permeable, the boundary is open, otherwise it is closed.

In the small strain theory, these conditions are expressed in terms of pore pressure (equal to zero if boundaries are drained) whereas, in the large strain theory, they are expressed in terms of void ratio.

The electrical boundary conditions are related to the applied voltage difference: the voltage is zero at the cathode and equal to its maximum value at the anode.

\subsection{Constitutive relationships}

In the numerical study, some constitutive relationships have been adopted to represent the main mechanisms that play a role in the complex electro-mechanical consolidation process. The theoretical models (mechanical consolidation models, electro-osmotic model) will be briefly described in the following sections.

Under unsaturated conditions, all transport coefficients involved in the EK process are strongly dependent on the degree of saturation of the soil. In this study, the mechanics of unsaturated soils has not been considered due to the complex solutions, so the degree of saturation is assumed to be 1 (i.e. only effective stresses are considered).

\subsubsection{Mechanical consolidation models}

\subsubsection{SMALL STRAIN THEORY - SS}

In $1 \mathrm{D}$ conditions, the application of a vertical load $q$ produces an identical increase of the total vertical stress $\left(\Delta \sigma_{\mathrm{v}}=q\right)$. Terzaghi's solution of the subsequent $1 \mathrm{D}$ consolidation process, written in terms of pore-water pressure $u$, takes the well-known form

$$
\text { 1. } \frac{\partial u}{\partial t}=c_{\mathrm{V}} \frac{\partial^{2} u}{\partial z^{2}}
$$

given the hypotheses of saturated and elastic soil, uncompressible water and solid particles, validity of Darcy's filtration law and constant permeability. The coefficient of consolidation $c_{\mathrm{v}}$ $\left(\mathrm{m}^{2} / \mathrm{s}\right)$ is defined as

2. $c_{\mathrm{v}}=\frac{k E_{\mathrm{ed}}}{\gamma_{\mathrm{w}}}$

where $k$ is the constant coefficient of permeability $(\mathrm{m} / \mathrm{s}) ; E_{\text {ed }}$ the constant oedometric constrained modulus $(\mathrm{kPa}) ; \gamma_{\mathrm{w}}$ is the specific weight of water $\left(\mathrm{kN} / \mathrm{m}^{3}\right)$

In the numerical code Lassec1, Equation 1 is solved with a finite-differences algorithm (explicit approach) giving a set of initial and boundary conditions. Consistently with the hypotheses used to write Equation 1, soil stiffness and permeability are kept constant throughout the process and can be quantified by way of the normal compression line (NCL) determined from oedometric tests (Figure 12(a)). 


\subsubsection{LARGE STRAIN THEORY - LS}

It is well known that in the case of very soft soils, which includes dredged sediments the 1D consolidation process has to be analysed by means of the large deformations theory proposed by Gibson et al. (1967). This theory allows the nonlinearity of the deformation and permeation processes to be taken into account, that is the variations of compressibility and permeability of the soil mass throughout the process, as well as the position of each material point in the soil mass during the development of the consolidation process. Under the assumptions of a saturated and homogeneous medium, 1D water flow and displacements, the absence of viscous components in the mechanical behaviour of the solid skeleton, incompressibility of the liquid and the solid phase, the validity of Darcy's law (but with a variable coefficient of permeability $k$ ), by imposing the conservation of mass, the ruling equation of $1 \mathrm{D}$ consolidation in large strain can be written in terms of void ratio $e$ as

3. $\left(1-G_{\mathrm{s}}\right) \frac{\mathrm{d}}{\mathrm{d} e} \frac{k(e)}{(1+e)} \frac{\partial e}{\partial z}-\frac{\partial}{\partial z}\left[\frac{k(e)}{\gamma_{\mathrm{w}}} \frac{1+e_{0}}{1+e} \frac{\partial \sigma^{\prime}}{\partial e} \frac{\partial e}{\partial z}\right]=\frac{1}{1+e_{0}} \frac{\partial e}{\partial t}$

Equation 3 is a second-order partial differential equation in which $z$ is the geometric variable; $G_{\mathrm{s}}$ is the soil specific gravity; $k(e)$ is the permeability function, expressed as a function of the current void ratio; and $\partial \sigma^{\prime} / \partial e$ is the current soil stiffness, to be calculated once the stress-strain behaviour is expressed through a derivable $\sigma^{\prime}(e)$ function.

The solution of Equation 3, with the specified initial and boundary conditions, allows the study of the evolution in time of the void ratio and the stress state (in terms of total $\sigma$ and effective $\sigma^{\prime}$ stresses, or of pore-water pressure $u$ ). In order to capture reasonably the high non-linearity of the two functions $e\left(\sigma^{\prime}\right)$ and $k(e)$, Znidarcic (Liu and Znidarcic, 1991) suggested to use the following constitutive relationships (Krizek and Somogyi, 1984)

4. $e=A\left(\sigma^{\prime}+Z\right)^{B}$

\section{5. $k=C e^{D}$}

where $A(1 / \mathrm{kPa}), B, C(\mathrm{~m} / \mathrm{h}), D$ and $Z(\mathrm{kPa})$ are material constants to be determined from laboratory results (Figures 12(a) and 12(b)) of sedimentation tests (for low stress ranges) and oedometric tests.

\subsubsection{Electro-osmotic model}

The following assumptions have been considered in the numerical model: (a) the soil is fully saturated; $(b)$ the velocity of the water flow due to electro-osmosis is directly proportional to the applied voltage gradient; $(c)$ the influence of electrophoresis, electrochemical reactions and streaming potential is neglected; $(d)$ the water movement in the soil is the result of the linear superposition of water flows due to electro-osmosis and to the hydraulic gradient (Wu et al., 2017).

In particular, in the special oedometric tests, it is not possible to eliminate the hydraulic gradient due to gravity, and thus the water flow is considered as the linear combination of the effect of hydraulic and EK heads.

The application of an electric gradient in a soil volume induces a water flow that can be related to the applied voltage $\Delta \Phi$ with a flow rule similar to the one caused by an hydraulic gradient (Darcy's equation). The form of such an equation is

6. $\quad q_{\mathrm{e}}=k_{\mathrm{e}} i_{\mathrm{e}} A_{\mathrm{c}}$

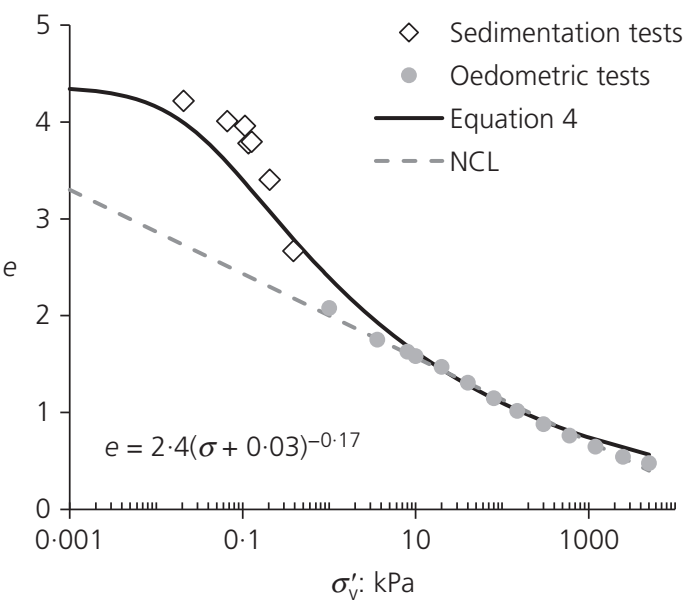

(a)

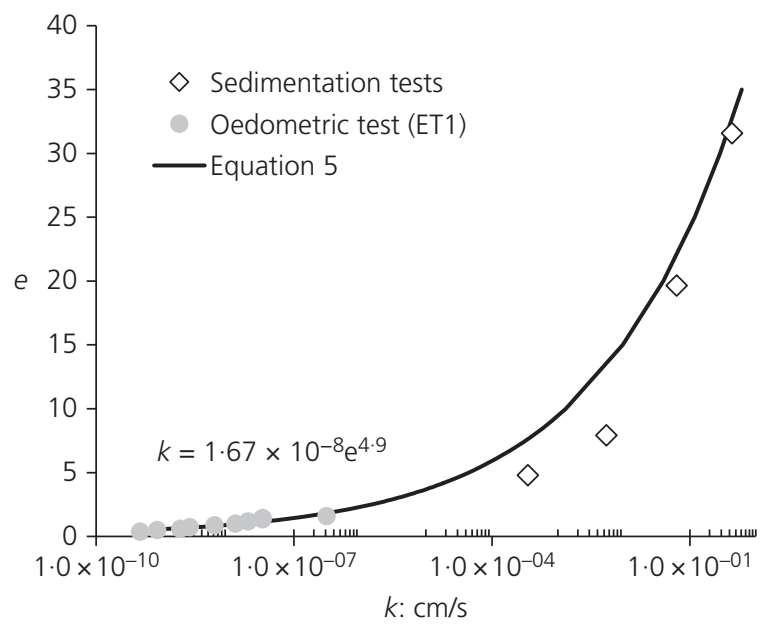

(b)

Figure 12. Soil constitutive relationships: (a) stress-strain; (b) permeability 
in which

$$
\text { 7. } i_{\mathrm{e}}=\frac{\Delta \phi}{\Delta L}
$$

$i_{\mathrm{e}}$ is the electrical potential gradient $(\mathrm{V} / \mathrm{m}) ; k_{\mathrm{e}}$ is the electroosmotic permeability $\left(\mathrm{m}^{2} / \mathrm{sV}\right) ; \Delta \phi$ is the applied electrical potential difference $(\mathrm{V}) ; \Delta L$ is the distance between the electrodes; and $A_{\mathrm{c}}$ is the area of the cross-section $\left(\mathrm{m}^{2}\right)$.

The electro-osmotic permeability $k_{\mathrm{e}}$ quantifies the flow rate of the pore fluid in response to the applied voltage gradient. One of the constitutive relationships for the electro-osmotic permeability is the one proposed by Mitchell and Soga (2005)

8. $k_{\mathrm{e}}=\frac{\zeta \varepsilon}{\eta} \frac{e}{1+e}$

in which $\zeta(\mathrm{V})$ is the so-called 'soil zeta potential'; $\varepsilon(\mathrm{F} / \mathrm{m})$ the dielectric constant of the pore fluid; $\eta$ (Pa s) is the dynamic viscosity of the fluid; and $e$ is the void ratio of the soil. Since these parameters are not easily quantified, Mitchell and Soga (2005) proposed to express $k_{\mathrm{e}}$ as

9. $k_{\mathrm{e}}=\beta \frac{e}{1+e}$

in which $\beta(=\zeta \varepsilon / \eta)$ is a material property to be calibrated on the results of oedometric tests.

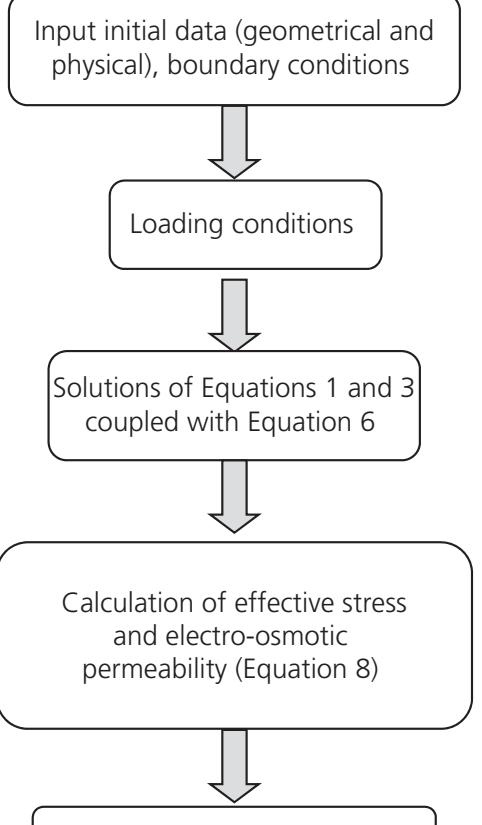

Calculation of soil settlement
The above model takes into account the non-linear variation of the electro-osmotic permeability $\left(k_{\mathrm{e}}\right)$. However, this parameter does not depend only on the void ratio, but is also related to other factors such as soil fabric, degree of saturation and chemical reactions (Mosavat et al., 2012). However, for this study, the modification of soil chemo-mechanical properties is neglected, being the application time of the electrical potential - and the electrical potential itself - very low.

\subsubsection{Lassec1}

The electro-mechanical consolidation process has been numerically simulated in Lassec1 by including the electro-osmotic model in the mechanical consolidation models (small strains SS or large strains LS). Figure 13 shows a simplified flow chart illustrating the basic algorithm of the numerical code.

The input data are: the number of layers into which the total height of the soil mass $\left(10 \cdot 3<H_{0}<11.0 \mathrm{~cm}\right)$ is divided $\left(n_{\mathrm{z}}\right)$, the number of time steps $\left(n_{\mathrm{t}}\right)$ and the total calculation time $(T)$. The number of layers and the number of time steps have been selected to guarantee the numerical stability (i.e. solution might be non-mesh-dependent).

As shown in the simplified flow chart, the input data are: the applied voltage $\left(\Delta \Phi_{0}(y)\right)$, the specific gravity of the solids $\left(G_{\mathrm{s}}\right)$, the parameters for the mechanical constitutive relationships ( $\beta, A, B, C, D$ and $Z$ for the Gibson equation and $\beta, E_{\text {ed }}, k$ for the Terzaghi equation), the boundary drainage conditions and the initial void ratio $\left(e_{0}\right)$. 
Once all the data inputs are given, Lassecl calculates the current soil void ratios (Gibson, Equation 3) or the pore pressures (Terzaghi, Equation 1) in each layer for the assigned initial loading condition (mechanical or electrical); in both cases (small or large strains), the code calculates the effective stresses within the soil volume, solving the constitutive relationships previously introduced. The average soil settlements $(s)$ and the corresponding new height $(H)$ of the soil volume are finally calculated for each time step, in an iterative mode.

\section{Models calibration}

As previously mentioned, Lassec1 can be used either in small or large strain conditions (SS or LS). In the SS condition, the values of the soil permeability coefficient $k$ and oedometric modulus $E_{\text {ed }}$ (necessary for the solution of Equation 1) have been computed by way of the NCL line established from the results of the oedometric tests M1 and M2 (Figure 12(a)), extrapolated to cover the low stress ranges too.

In the LS condition, the two constitutive relationships $e\left(\sigma^{\prime}\right)$ and $k(e)$ have been calibrated, respectively, on the results of oedometric and sedimentation tests (Figures 12(a) and 12(b)).
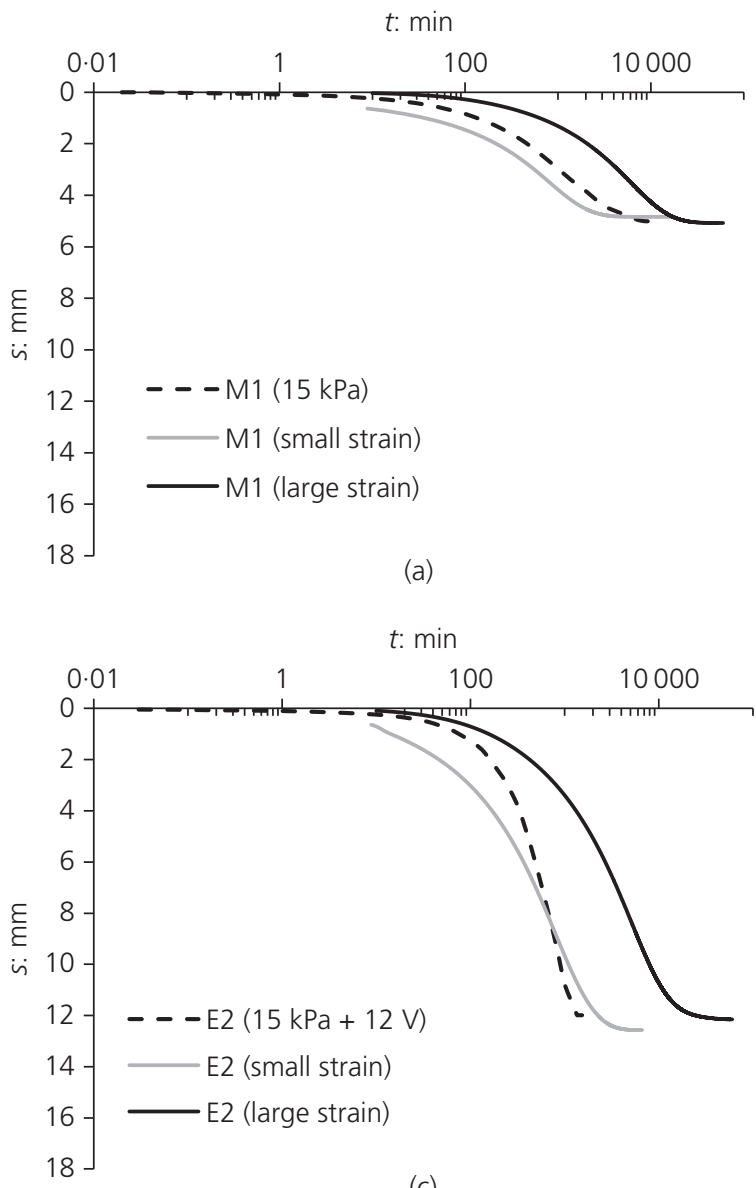

(c)
It can be noted that for vertical stresses larger than $10 \mathrm{kPa}$, there are no differences between the two compressibility laws (Equation 4 and NCL). Otherwise, for very low vertical stresses, the NCL line is unable to capture the high values of the void index measured in the sedimentation tests.

Regarding the electro-osmotic permeability $k_{\mathrm{e}}$, which rules the water flow induced by the applied voltage gradient (Equation 6), it depends on the degree of saturation of the soil, which is unknown in these tests. For this reason, its value $\left(k_{\mathrm{e}}=4.8 \div 5 \times 10^{-6} \mathrm{~m}^{2} / \mathrm{hV}\right.$ ) has been quantified by way of a back analysis of the experimental results, as shown in the following.

\section{Numerical simulations}

Some experimental results carried out in the EdS have been reproduced by means of numerical simulations (Lassec1) in order to verify the numerical code effectiveness in reproducing the complex electro-mechanical consolidation process observed in the laboratory tests.

Figure 14 shows the soil settlements against time measured in the tests M1, E1, E2 and E3 (Table 2) and the simulations

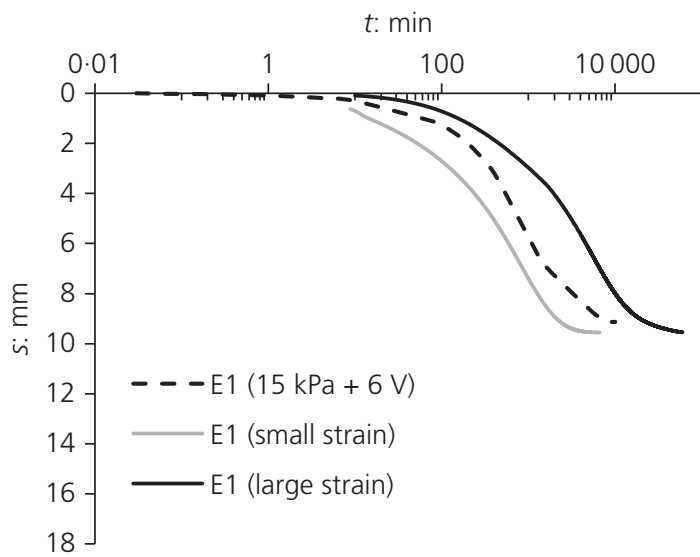

(b)

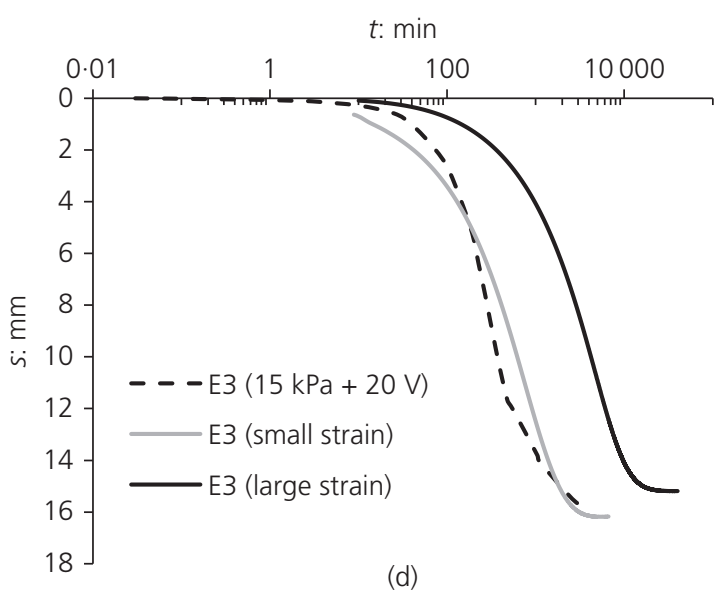

(d)

Figure 14. Comparison between numerical simulations and experimental data (Table 2): soil settlements (s) against time (t): (a) test M1; (b) test E1; (c) test E2; (d) test E3 


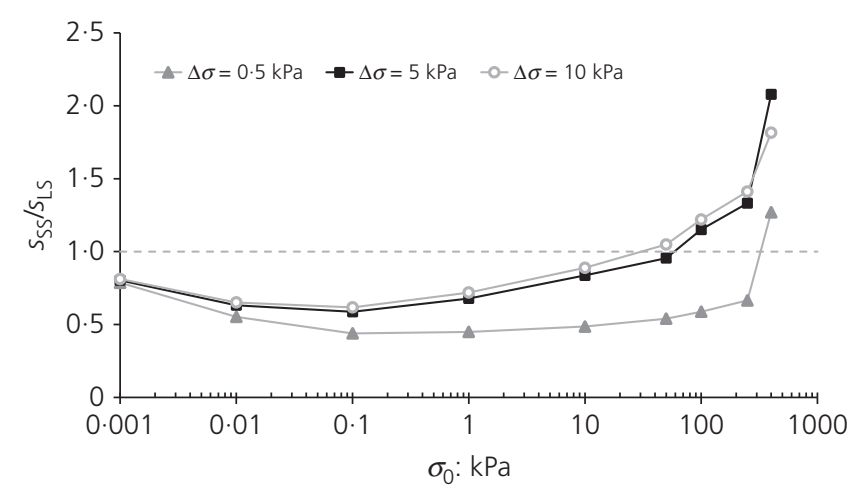

Figure 15. Numerical results: soil settlements in small strains ( $\left.s_{s s}\right)$ and large strains condition $\left(s_{L S}\right)$

obtained with Lassec1. It can be observed that both models (small strains and large strains) reproduce reasonably well the experimental soil settlements evolution in time. The overall comparison highlights that in the stress ranges tested in the laboratory (8-15 kPa, 15-30 kPa, Table 2), there are no significant differences between small and large strains consolidation models, even though the solution with the large strains systematically slightly overestimates the time needed to reach completion of the consolidation process. This result was predictable because in these stress ranges, as previously mentioned, the two adopted soil compressibility laws $e=e\left(\sigma^{\prime}\right)$ are overlapped (Figure 12(a)). A much greater difference should emerge for lower stress levels, where the two compressibility laws are very different.

With this aim, a parametric analysis has been conducted with Lassec1, by using both small and large strains models, starting from different initial vertical stress $\left(\sigma_{0}\right)$ and considering three different load steps $(\Delta \sigma=0 \cdot 5,5$ and $10 \mathrm{kPa})$. The numerical results have been plotted in Figure 15 in terms of the ratio between the soil settlements in the small strains condition $\left(s_{\mathrm{SS}}\right)$ and the ones obtained in the large strains condition $\left(s_{\mathrm{LS}}\right)$ against the initial vertical stress. This ratio becomes 1 when the two numerical models give the same final soil settlement: as might be predicted, the two models give different results at low stress levels (as is the case for freshly dredged materials), as this difference is linked to the stress condition (initial vertical stress and stress increment).

\section{Conclusions}

A 1D finite-difference numerical code Lassec1 has been developed to solve in a coupled way the mechanical and electroosmotic consolidation process of soft clayey soils. The code was validated by means of comparison with experimental data retrieved from tests in a special oedometric device. The code solves the consolidation process with two models (SS and LS) that have different pros and cons. The large strain model LS is able to capture the behaviour of an extremely compressible soil, at the price of a larger number of parameters being needed; the small strain model SS is strictly applicable for cases in which the displacements are not so large, but has the enormous advantage of needing fewer parameters and of belonging to the cultural background of any geotechnical engineer. Of course, for the small strain solution, the calibration of the constant stiffness is extremely critical. The question of which should be preferred, or what is the largest strain level to which Terzaghi's simpler model can be used, is of paramount importance, and has to some extent been addressed in general terms in the past (Cargill, 1982; Gibson et al., 1967).

Based on the numerical results given by Lassec1, some comments can be made.

- As long as the consolidation stage under analysis is in a quasi-linear range for the stress-strain behaviour and with a quasi-constant permeability coefficient, the simpler small strain theory can be used.

- If the consolidation process starts from extremely low stress levels (as is the case, for instance, for freshly dredged materials), the non-linearity becomes important (Figure 12(a)) and the non-linear (large strains) consolidation theory has to be preferred.

- When using the non-linear consolidation model, a reliable calibration of the constitutive equations representing the stress-strain and permeability functions (Equations 4 and 5) is important. With this aim, the conventional oedometric tests have limitations, as they cannot be used for extremely low stress levels (close to zero), and more sophisticated tests have to be carried out.

- The electrochemical processes (electrolysis, electro-osmosis, electro-migration and electrophoresis) induce a significant irreversible change in the physico-chemical and mechanical properties of the treated soil. The numerical code is unable to take into account all of these modifications as yet, but the ongoing research is oriented towards this aspect.

\section{REFERENCES}

Alshawabkeh AN, Sheahan TC and Wu X (2004) Coupling of electrochemical and mechanical processes in soils under DC fields. Mechanics of Materials 36(5-6): 453-465.

Apitz SE (2010) Waste or resource? Classifying and scoring dredged material management strategies in terms of the waste hierarchy. Journal of Soils and Sediments 10(8): 1657-1668.

Bjerrum L, Moum J and Eide O (1967) Application of electro-osmosis to a foundation problem in Norwegian quick clay. Géotechnique 17(3): 214-235, https://doi.org/10.1680/geot.1967.17.3.214.

Cargill KW (1982) MPGL-82-3: Consolidation of Soft Layers by Finite Strain Analysis. Geotechnic Laboratory, Waterways Experiment Station, Vicksburg, MS, USA.

Casagrande L (1948) Electro-osmosis in soils. Geotechnique 1(3): 159-177, https://doi.org/10.1680/geot.1949.1.3.159.

Esrig MI (1968) Pore pressures, consolidation and electrokinetics. Journal of the Soil Mechanics and Foundations Division, ASCE 94(7): 899-921.

Flora A, Gargano S, Lirer S and Mele L (2016) Effect of electro-kinetic consolidation on fine grained dredged sediments. Procedia Engineering 158(6): 3-8. 
Flora A, Gargano S, Lirer S and Mele L (2017) Experimental evidences of the strengthening of dredged sediments by electroosmotic consolidation. Geotechnical and Geological Engineering 35(6): 2879-2890.

Gargano S (2017) LASSEC1 Manual. University of Napoli Federico II, Naples, Italy, Internal report.

Gibson RE, England GL and Hussey MJL (1967) The theory of one-dimensional consolidation of saturated clays: 1. Finite non-linear consolidation of thin homogeneous layers. Géotechnique 17(6): 261-273, https://doi.org/10.1680/geot.1967.17.3.261.

Gray D and Mitchell K (1967) Fundamental aspect of electro-osmosis in soils. Journal of the Soil Mechanics and Foundations Division 93(6): 209-236.

Hu L, Wu W and Wu H (2012) Numerical model of electro-osmotic consolidation in clay. Géotechnique 62(6): 537-541, https://doi.org/10.1680/geot.11.T.008

Krizek RJ and Somogyi F (1984) Perspectives on modelling consolidation of dredged materials. In Proceedings of the Symposium on Sedimentation Consolidation Models: Prediction and Validation, San Francisco, CA, USA (Yong RN and Townsend FC (eds)). ASCE, New York, NY, USA, pp. 296-332.

Lee M (2007) Electrically induced settling and consolidation behaviour of soft soil. KSCE Journal of Civil Engineering 11(4): 185-191.

Lewis WR and Humpheson C (1973) Numerical analysis of electro-osmotic flow in soils. Journal of the Soil Mechanics and Foundations Division ASCE 99(8): 603-616.

Lirer S, Liguori B, Capasso I, Flora A and Caputo D (2017) Mechanical and chemical properties of composite materials made of dredged sediments in a fly-ash based geopolymer. Journal of Environmental Management 191: 1-7.

Liu JC and Znidarcic D (1991) Modeling one-dimensional compression characteristics of soils. Journal of Geotechnical Engineering 117(1) $162-169$.
Lo KY, Ho KS and Inculet II (1991) Electro-osmotic strengthening of soft sensitive clays. Canadian Geotechnical Journal 28(1): $62-73$.

Lockhart NC (1983) Electroosmotic dewatering of clays. II. Influence of salt, acid and flocculants. Colloids and Surfaces 6(3): 253-269.

Mitchell JK (1993) Fundamentals of Soil Behavior, 2nd edn. John Wiley \& Sons, New York, NY, USA.

Mitchell JK and Soga K (2005) Fundamentals of Soil Behavior, 3rd edn. John Wiley, New York, NY, USA.

Mosavat N, Oh E and Chai G (2012) A review of electrokinetic treatment technique for improving the engineering characteristics of low permeable problematic soils. International Journal of GEOMATE 2(2): 266-272.

Ortenblad A (1930) Mathematical theory of the process of consolidation of mud deposits. Journal of Mathematics and Physics 9(2): 73-149.

Reddy KR, Urbanek A and Khodadoust AP (2006) Electroosmotic dewatering of dredged sediments: bench-scale investigation. Journal of Environmental Management 78(2): 200-208.

Rittirong A and Shang JQ (2008) Numerical analysis for electroosmosis consolidation in two-dimensional electric field. In Proceedings of the 18th International Ocean and Polar Engineering Conference, Vancouver, Canada. International Society of Offshore and Polar Engineers, Mountain View, CA, USA, pp. 566-572.

Terzaghi K (1943) Theoretical Soil Mechanics. John Wiley and Sons, Inc., New York, NY, USA.

Wan TY and Mitchell JK (1976) Electro-osmotic consolidation of soils. Journal of the Geotechnical Engineering Division ASCE 102(5): 473-491.

Wu H, Hu L and Wen Q (2017) Numerical simulation of electro-osmotic consolidation coupling non-linear variation of soil parameters. Computers \& Geosciences 103: 92-98.

Yeung AT (1994) Electro-kinetic flow process in porous media and their applications. Advances in Porous Media 2: 307-393.

\section{How can you contribute?}

To discuss this paper, please email up to 500 words to the editor at journals@ice.org.uk. Your contribution will be forwarded to the author(s) for a reply and, if considered appropriate by the editorial board, it will be published as discussion in a future issue of the journal.

Proceedings journals rely entirely on contributions from the civil engineering profession (and allied disciplines). Information about how to submit your paper online is available at www.icevirtuallibrary.com/page/authors, where you will also find detailed author guidelines. 